\title{
APPROXIMATION PROPERTIES OF COMBINATION OF MULTIVARIATE AVERAGES ON TRIEBEL-LIZORKIN SPACES
}

\section{SHAOYONG HE}

Abstract. The purpose of this paper is to establish the rate of approximation of the combination of some generalized multivariate average on Triebel-Lizorkin spaces and obtain its equivalent relation to the K-functionals. These results significantly generalize some known results in the literatures.

Mathematics subject classification (2010): 41A17, 42B35.

Keywords and phrases: K-functional, Triebel-Lizorkin space, multivariate average.

\section{REFERENCES}

[1] R. Alabern, J. Mateu And J. Verdera, A new characterization of Sobolev spaces on $\mathbb{R}^{n}$, Math. Ann. 354, 2 (2012), 589-626.

[2] E. Belinsky, F. Dai And Z. Ditzian, Multivariate approximating average, J. Approx. Theory, 125, 1 (2003), 85-105.

[3] W. CAO, J. CHEN AND D. FAN, Boundedness of an oscillating multiplier on Triebel-Lizorkin spaces, Acta Math. Sin. (Engl. Ser.), 26, 11 (2010), 2071-2084.

[4] A. Carbery, J. L. Rubio de Francia And L. Vega, Almost everywhere summability of Fourier integrals, J. Lond. Math. Soc., 38, 3 (1988), 513-524.

[5] J. CHEN, D. FAN AND L. Sun, Hardy space estimates for the wave equation on compact Lie groups, J. Funct. Anal., 259, 12 (2010), 3230-3264.

[6] Y. K. CHO, Continuous characterization of the Triebel-Lizorkin spaces and Fourier multipliers, Bull. Korean Math. Soc., 47, (2010), 839-857.

[7] F. Dai And Z. Ditzian, Combinations of multivariate average, J. Approx. Theory, 131, 2 (2004), 268-283.

[8] Z. DitZIAN AND A. PRYMAK, Convexity, moduli of smoothness and a Jackson-type inequality, Acta Math. Hunger., 130, 3 (2011), 254-285.

[9] Z. DitziAn AND K. RunOvskit, Realization and smootheness related to the Laplacian, Acta Math. Hunger., 93, 3 (2001), 189-223.

[10] D. FAn, Z. LOU AND Z. WANG, A note on iterated spherical average on Lebesgue spaces, Nonlinear Anal., 180, (2019), 170-183.

[11] D. FAN AND F. ZHAO, Approximation properties of combination of multivariate averages on Hardy spaces, J. Approx. Theory, 223, (2017), 77-95.

[12] M. Frasier AND B. JAWERTH, A discrete transform and decompositions of distribution spaces, J. Funct. Anal., 93, 1 (1990) 34-170.

[13] L. Grafakos, Class Fourier Analysis, second ed., in Graduate Texts in math. vol. 249, Spinger, New York, 2008.

[14] Z. LiU AND S. LU, Applications of Hörmander multiplier theorem to approximation in real Hardy space, Lecture Notes in Math., 1494, (1991), 119-129.

[15] A. Miyachi, On some singular Fourier multipliers, J. Fac. Sci. Univ. Tokyo Sect. IA Math., 28, (1981) 267-315.

[16] J. PERAL, $L^{p}$ estimates for the wave equation, J. Funct. Anal., 36, 1 (1980), 114-145.

[17] J. L. RUBIO DE FRANCIA, Weighted norm intequalitities for homogeneous families of operators, Trans. Amer. Math. Soc., 275, 2 (1976), 2174-2175. 
[18] E. M. Stein, Maximal functions: Spherical means, Proc. Nat. Acad. Sci. U.S.A. 73, (1976), 21742175.

[19] E. M. SteIn, Harmonic Analysis: Real-Variable Meheods, Orthogonality, and Oscillatory Integrals, Princeton Univ. Press, Princeton, N. J., 1973.

[20] E. M. Stein AND G. WeIss, Intoduction to Fourier Analysis on Euclidean Spaces, Princeton Univ. Press, Princeton, N. J., 1971.

[21] D. Yang, YuAn, Wen And C. Zhuo, Fourier multipliers on Triebel-Lizorkin-type spaces, J. Funct. Spaces Appl., 2012, Art. ID 431016, 37 pp. 